\title{
Deltoid triceps transfer and functional independence of people with tetraplegia
}

\author{
AL Dunkerley*,1, A Ashburn ${ }^{1}$ and EL Stack ${ }^{1}$ \\ ${ }^{1}$ University Rehabilitation Research Unit, University of Southampton, UK
}

Study design: Matched case control study. Setting: Two regional spinal units-Salisbury, UK (surgical centre) and London, UK (control centre).

Objective: To compare the functional independence and wheelchair mobility of spinal cord injured subjects, post deltoid triceps transfer, with matched control subjects.

Methods: Two matched groups of subjects, with tetraplegia resulting in triceps paralysis, were studied. The surgical group consisted of five of the six patients who had previously undergone deltoid triceps transfer at Salisbury. The control group $(n=6)$ had not undergone surgical intervention but were comparable with respect to level of lesion, age, age at injury and duration of disability. All subjects completed standardised assessments of activities of daily living (Functional Independence Measure-FIM) and wheelchair mobility (10 m push and figure of 8 push). Surgical subjects completed additional questions, regarding the perceived effects of surgery on function.

Results: It was not possible to demonstrate absolute functional differences with the chosen outcome measures in this small series of matched case controls. All surgical subjects cited specific functional improvements since surgery and recommended the procedure. However the FIM lacked sufficient sensitivity to detect these changes.

Conclusion: Further investigation of the functional outcome of deltoid triceps transfer in tetraplegia is warranted. Development of more sensitive outcome measures would be useful. Spinal Cord (2000) 38, 435-441.

Keywords: tetraplegia; deltoid triceps transfer; functional independence; spinal cord injury

\section{Introduction}

Upper limb paralysis, following cervical spinal cord injury (SCI) presents difficulties in activities of daily living (ADL) e.g. dressing and washing. In some cases, individuals can learn to modify their motor behaviour to best suit their physical capacities ${ }^{1}$ and so realise further functional abilities: in particular, wheelchair propulsion, self feeding and sometimes, turning in bed, transfers and driving with hand controls. ${ }^{2}$ Patients themselves regard improved upper limb function as a top priority in relation to other aspects of their disability. ${ }^{3}$ Following a study of 29 tetraplegics, Welch et $a l^{4}$ concluded that voluntary control of triceps was a significant determinant in the ability to perform self care tasks. These authors studied two groups-those with wrist extensors as the lowest functioning muscle and those with triceps as the lowest functioning muscle. In all cases muscle power was sufficient to produce movement against gravity with some resistance. All

*Correspondence: A Dunkerley, C/o University of Southampton Rehabilitation Research Unit, Level E (886), Centre Block, Southampton General Hospital, Tremona Road, Southampton, SO16 6YD, UK individuals studied had normal shoulder power, elbow flexion and wrist extension. In addition, the second group, with functional triceps, had normal or near normal elbow extension. Results showed that a greater proportion of subjects with triceps control were independent in activities such as dressing and bed mobility.

A tetraplegic person with a paralysed triceps muscle has reduced upper extremity strength and stability. ${ }^{5}$ There are difficulties in positioning and stabilising the arm as a result. Although gravity may assist elbow extension, it may also cause it to buckle, allowing the hand to suddenly strike the face or forehead. Tendon transfer has the potential to replace the action of paralysed muscle. The main principles of surgery have been outlined elsewhere. ${ }^{6,7}$ The deltoid triceps transfer, pioneered over 20 years ago, ${ }^{8}$ is considered useful in individuals with SCI at the level of $\mathrm{C} 5$ and $\mathrm{C} 6$ where there is absent or limited elbow extension. ${ }^{9-11}$ The posterior portion of the deltoid muscle is used to replace the action of triceps in elbow extension. Posterior deltoid is detached from its insertion and re-joined to the triceps aponeurosis using either a free tendon or artificial graft. 
Surgical restoration of active elbow extension in patients with cervical SCI is thought beneficial in increasing functional ability but has been poorly evaluated. Improved reach and stability have aided personal care, such as grooming and eating. ${ }^{10-14}$ Some authors have noted sufficient strength to allow weight shifts to relieve pressure, ${ }^{5,9,10,13,14}$ although it has not been observed as particularly useful in improving subjects' ability to transfer. Elbow extension may assist in getting into a sitting position, turning in bed and also bracing the body in the event of falling forward in a wheelchair. ${ }^{8,14}$ Improvements in recreational, educational and social functioning as well as employment opportunities are difficult to quantify. However, facilitation of driving, swimming and writing have been reported. ${ }^{10-12,14,15}$

The difficulties in assessing the outcome of upper limb surgery have been highlighted. ${ }^{8,9,16,17}$ Moberg $^{11}$ stated that an improvement in control not power, is essential in evaluating the effect of deltoid triceps transfer. However, outcomes are commonly demonstrated by power measured on strain gauges, torques produced in muscle contraction and range of elbow extension. There is a relative dearth of research focusing on measurable functional gains. Methods of patient evaluation vary throughout the literature making comparison of findings from different researchers difficult. Improvements in wheelchair control and mobility have been reported ${ }^{5,9,13,14,18,19}$ yet it appears that objective testing was not used to support these observations. Functional independence has been assessed by interview or questionnaire in some studies and by locally devised ADL scales in others. ${ }^{13,20}$ Few studies ${ }^{17,21}$ have used existing measures such as the Functional Independence Measure (FIM). ${ }^{22}$

\section{Objective}

The aims of the study were to describe and compare the functional capacity of a group of people with tetraplegia with and without deltoid triceps transfer surgery. No previous studies have compared operated and non-operated subjects with the same diagnosis. The hypothesis was: people with tetraplegia who have undergone deltoid triceps transfer surgery have greater functional independence than a matched non-intervention control group. This paper reports some of the results from a larger study investigating upper limb tendon transfer surgery in tetraplegia. ${ }^{23}$

\section{Method}

\section{Subjects}

A group of subjects who had undergone deltoid triceps transfer at the Duke of Cornwall Spinal Treatment Centre, Salisbury were compared with a group of nonsurgical (control) subjects in a matched case-control study. All subjects had sustained a traumatic SCI resulting in non-progressive motor complete tetraplegia between the levels of $\mathrm{C} 4-6$. At the time of the study six patients had undergone simple deltoid triceps surgery. Control subjects were recruited from the Royal National Orthopaedic Hospital, Stanmore, a spinal unit with similarities in the philosophy and practice of rehabilitation. The aim was to match each surgical subject, by the following variables, to two controls where possible:

- Level of injury and residual motor and sensory function according to the International Classification $^{24}$

- Age within 5 years

- Time since injury (as closely as possible within age band)

- Gender

The same exclusion criteria used to identify patients for surgery were applied to control subjects. Also excluded were those unable to propel a manual wheelchair as they would be unable to complete part of the assessment. For practical reasons, subjects were UK residents and spoke English. Ethical approval was granted at both centres. Informed consent to take part was given by each subject.

\section{Outcome measures}

An adapted Functional Independence Measure $(\text { FIM })^{22}$ was used to quantify the performance of activities of daily living. The scoring system accounts for the use of adaptive equipment and various levels of assistance likely to be encountered in a tetraplegic group. Reliability and validity of this scale have been established $^{22,25}$ and it has been endorsed by the American Spinal Injuries Assocation (ASIA) as a standard measure of function in SCI. Good clinical interrater agreement has been reported. ${ }^{26}$ The conventionally scored FIM, using clinician observation to assign scores, was not practical in the present study. A self reporting version of the FIM, developed and found to be reliable in a pilot study, ${ }^{23}$ was devised as an alternative. It was scored according to the subject's description of ability. Self reporting has been documented elsewhere ${ }^{24,27-30}$ with substantial agreement between clinician and patient rated scores. The complete FIM consists of 18 items grouped in six sections and scored on a seven level scale (where 1 indicates total dependence and 7 indicates total independence). The sections of communication and social cognition were not deemed relevant in the context of this study and were omitted. Subjects were scored on a total of 13 items under four headings: self care, sphincter control, mobility and locomotion.

Two further methods of objective measurement of wheelchair propulsion were used to augment the scores from the FIM locomotion section: the $10 \mathrm{~m}$ push and the figure of 8 push. Each subject completed the tests in his own manual wheelchair. It was assumed that chairs were set up optimally for the users. Both tests 
were conducted on a hard, smooth and level floor. Subjects were instructed to traverse each course as fast as possible. The $10 \mathrm{~m}$ push was considered the equivalent of the $10 \mathrm{~m}$ walk ${ }^{31}$ in ambulant and ablebodied subjects. It was measured over a straight course of $16 \mathrm{~m}$. The time taken to push the middle $10 \mathrm{~m}$ length was recorded. Subjects completed one practice push, followed by a test push with a rest between if required. The figure of 8 push was a test of manoeuvring skills in a tight space. Two obstacles were placed two metres apart with a central marker between them. The subject started the test from rest, at the central marker, and was instructed to negotiate the course in a figure of eight pattern. The time taken to traverse this course was recorded. One practice and one test push were completed.

Surgical subjects answered three questions regarding the positive and negative effects of surgery on function and if they would recommend the procedure to others. The questionnaire had been piloted.

\section{Data analysis}

The mean of each set of controls was calculated and compared to the corresponding surgical match. All statistical tests used analysis of matched pairs. The difference in FIM scores was analysed using the Wilcoxon Matched Pairs Signed Ranks Test. The paired sample $t$-test was used in analysis of mobility tests and to compare surgical and control groups on demographic details. Significance levels were set at $5 \%$.

\section{Results}

\section{Subjects}

Five of the six patients who had undergone deltoid triceps transfer surgery agreed to participate. The sixth patient was unable to take part due to illness. Twentytwo potential control subjects were identified to match the surgical subjects. A letter was sent initially to 15 control subjects (taking the three best matches to each surgical subject). Letters were sent to further subjects in the event of negative replies and non-respondents. In total, 20 subjects were contacted, of whom 15 responded-10 of these positively. Three control subjects were found to be unsuitable on telephone contact because none were able to self propel a manual wheelchair. One subject replied positively after data collection had been completed. These four subjects were not assessed. No reasons were given by those who declined to participate.

Six control subjects were assessed. It was therefore not possible to match two to each surgical subject as was originally intended. Two subjects were matched to two controls, two were matched to a single control and one subject remained unmatched. The unmatched subject's results were not used in any analysis but were observed for interest.

All subjects were male and had sustained complete cervical SCI. Demographic details are shown in Table 1. There were no significant differences between surgical and control subjects for age, age at injury and time since injury.

Table 2 indicates the muscle strength of surgical subjects and controls using the International Classification. ${ }^{24}$ This system grades the subject separately for each upper limb, assigning figures for left and right to indicate the remaining muscles distal to the elbow with power of at least MRC grade 4, i.e. suitable for transfer. For example, where brachioradialis is the only muscle of sufficient strength, the subject is graded ' 1 '. Grades 2-9 correspond to additional muscles, i.e ' 2 ' corresponds to extensor carpi radialis longus (ECRL) in addition to brachioradialis (BR), and ' 3 ' to extensor carpi radialis brevis as well as ECRL and BR. Control subjects were tested manually by the researcher (AD).

Table 2 Muscle strength of surgical subjects and controls using the International Classification ${ }^{24}$

\begin{tabular}{lccc}
\hline Case & Surgical subject & Control 1 & Control 2 \\
\hline 1 & $\underline{\mathrm{R} 2} \underline{\mathrm{L} 1}$ & $\mathrm{R} 2 \mathrm{~L} 1$ & $\mathrm{R} 1 \mathrm{~L} 2 *$ \\
2 & $\underline{\mathrm{R} 1} \mathrm{~L} 3$ & $\mathrm{R} 2 \mathrm{~L} 1 *$ & - \\
3 & $\underline{\mathrm{R} 3} \mathrm{~L} 3$ & $\mathrm{R} 3 \mathrm{~L} 3$ & $\mathrm{R} 3 \mathrm{~L} 3$ \\
4 & $\underline{\mathrm{R} 3} \underline{\mathrm{L} 1}$ & $\mathrm{R} 3 \mathrm{~L} 1$ & - \\
5 & $\underline{2}$ & \multicolumn{2}{c}{ No matches } \\
\hline
\end{tabular}

Three surgical subjects presented with asymmetrical neurology in that one limb was marginally stronger than the other. This was taken into account when subjects were matched and most were matched exactly. However two controls had the opposite asymmetry as the surgical subject $(*)$. R, right, L, left, surgical side underlined

Table 1 Demographic details

\begin{tabular}{|c|c|c|c|c|c|c|c|}
\hline Variable & $\begin{array}{l}\text { Range } \\
\text { (years) }\end{array}$ & $\begin{array}{c}\text { gical gr } \\
\text { Mean } \\
\text { (years) }\end{array}$ & $\begin{array}{c}S D \\
\text { (years) }\end{array}$ & $\begin{array}{l}\text { Range } \\
\text { (years) }\end{array}$ & $\begin{array}{c}\text { ntrol gr } \\
\text { Mean } \\
\text { (years) }\end{array}$ & $\begin{array}{c}S D \\
\text { (years) }\end{array}$ & $\mathrm{P}$ Value \\
\hline Age & $23-37$ & 31.0 & 6.33 & $29-38$ & 33.9 & 3.75 & 0.45 \\
\hline Age at injury & $18-27$ & 22.3 & 3.78 & $21-23$ & 21.6 & 0.95 & 0.71 \\
\hline Time since injury & $5-16$ & 8.8 & 4.99 & $7.5-15$ & 12.1 & 3.33 & 0.35 \\
\hline Time since surgery & $1.5-3$ & 2.5 & 0.71 & - & - & - & - \\
\hline
\end{tabular}

$\mathrm{SD}$, standard deviation 
Results of FIM score

Surgical and control subjects scored identically on six items. All scored 5 for eating, 1 for dressing lower body, bowel management, toilet transfers and locomotion (stairs) and 6 for locomotion (wheelchair). Since there were no differences in these outcomes, no further analysis was carried out on these data. Four pairs of data were analysed using the Wilcoxon Matched Pairs Signed Ranks Test on the seven remaining sections of the FIM (grooming, bathing, upper body dressing, toileting, bladder management, transfers to bed, chair and wheelchair, transfers to bath and shower) and the total score. Surgical subjects tended towards higher scores than controls in two areas-grooming and upper body dressing, although statistically significant differences were not found $(P=0.18$ and $P=0.109$ respectively).

\section{Results of mobility tests}

All subjects used lightweight wheelchairs. In the $10 \mathrm{~m}$ push, two of the surgical subjects (cases 3 and 4) were faster than their paired controls, while two performed similarly. In the figure of 8 push, one surgical subject was unable to steer the complete course, therefore only three pairs of data were analysed. Again, the same two surgical subjects were faster than their paired controls. Subjects' performances on both tests were not significantly different $(P=0.256, P=0.432)$ (see Table 3, Figures 1 and 2).

\section{Questionnaire}

Subjective information was gathered from the five surgical subjects using a questionnaire which explored three questions:

(a) Has the surgery on your arm(s) made a difference to your ability to carry out day to day tasks?

(b) Has the surgery on your arm(s) enabled you to do any new activities?

(c) Would you recommend your operation to another person in the same situation?

All subjects gave positive responses to the questions. Subjects reported improvements in reach, strength, control, flexibility and stability, resulting in more even propelling power and the ability to move the duvet for example. One subject felt that further improvements were limited by weakness in the hand

Table 3 Results of mobility tests

\begin{tabular}{lcc}
\hline & 10 m push & $\begin{array}{c}\text { Figure of } 8 \text { push } \\
\text { Subject group }\end{array}$ \\
Mean $( \pm \mathrm{SD})(\mathrm{s})$ & Mean $( \pm \mathrm{SD})(\mathrm{s})$ \\
\hline Surgical & $13.64( \pm 10.95)$ & $17.92( \pm 7.95)$ \\
Control & $18.25( \pm 7.43)$ & $25.17( \pm 4.97)$ \\
$P$ value & 0.256 & 0.432 \\
\hline
\end{tabular}

$\mathrm{SD}$, standard deviation

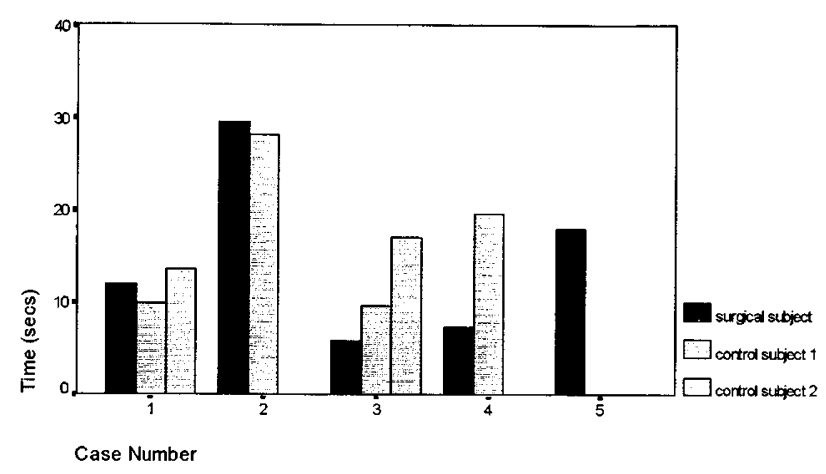

Figure $110 \mathrm{~m}$ push time

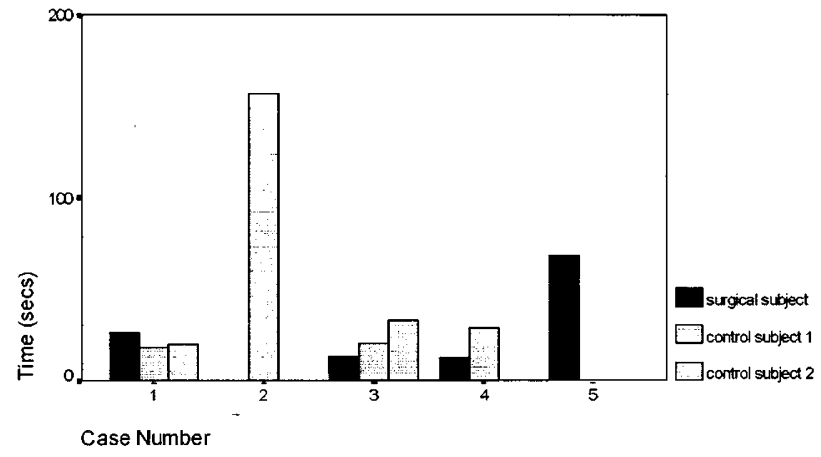

Figure 2 Figure of 8 push time

and wrist and root pain in the thumb. However he did indicate that surgery had helped him functionally. Several activities had been facilitated: writing, wheelchair propulsion, typing and use of computer, as well as leisure pursuits such as swimming, fishing, pool, bowling and even use of the controls in flying a light aircraft. One subject (with no active elbow extension prior to surgery) no longer required assistance to light a cigarette. $\mathrm{He}$ had enough stability to maintain his elbow position while holding an adapted lighter. The same subject could also right himself in his wheelchair if he fell forwards. Prior to surgery he was either accompanied at all times or strapped into his wheelchair. Two subjects now had the confidence to consider trying new skills, namely driving and archery. All subjects would recommend the procedure believing that there was nothing to lose and it was worth a short hospital stay to get an improvement in function. The increase in confidence and independence was valued greatly. Subjects emphasised the importance of realistic expectations of surgical intervention. Several had been asked to talk to prospective surgical candidates about their experiences and felt this to be worthwhile for those considering surgery. 


\section{Discussion}

\section{Sample}

All subjects in the study were male, with a mean age at injury of 22.3 years in the surgical group, and 21.6 years in the control group. Spinal cord injury occurs most frequently in males in their late teens and early twenties. ${ }^{32}$ The samples were felt to be representative of the diagnostic group and were demographically similar to those in previous studies. $7,13,16,18,19$

There is a substantial amount of published literature in the field of tendon transfer surgery but none comparing surgical and non-surgical subjects. Therefore some of the difficulties of subject recruitment and matching may not have been encountered by previous authors. A number of individuals expressed interest in the study but did not wish to participate. It is possible that those subjects felt that they were unable to provide useful information, given the nature of their disability. Several used power chairs for the majority of the time and, although they also had a manual chair, were not confident to transfer for the duration of the assessment. Individuals with high cervical lesions can be very independent using a power chair. It is possible that involvement in the study may have accentuated the disability in some cases. Surgery was not an available option for the control subjects at the time of the study, but several were keen to find out if they might benefit.

The surgical subjects responded more promptly to the correspondence. No reminders were sent. It is postulated that they had a desire to share their experiences of surgery and demonstrate its effect so that others may benefit. All subjects commented positively about surgery. It is not known whether subjects would have participated so readily in the research if their perceptions were negative.

\section{Assessments}

In this study, all surgical subjects scored identically in the FIM areas of eating, lower body dressing, locomotion, bowel management and toilet transfers. All subjects required some help cutting food which limited their scores. Deltoid triceps surgery may have improved the control of the limb while eating, but the FIM was not sensitive to this. Lower body dressing, bathing and toileting are physically demanding and time consuming activities for an individual with tetraplegia, requiring good balance while changing position. Realistically, upper limb surgery cannot purport to address these issues. In view of the energy and time involved, many tetraplegics will opt for assistance in order that more fulfilling activities can be undertaken. ${ }^{4}$ Maximum FIM score for wheelchair locomotion is achieved by controlling either a manual or power chair over a given distance. This may involve physically pushing the chair or using a joystick electric control. All subjects in this study were able to score the maximum possible, despite observable differences between them. As expected, all subjects scored the minimum for locomotion on stairs. Methods of bowel and bladder management are dependent in part on the nature of the neurological involvement, therefore, deltoid triceps transfer cannot necessarily be influential. The use of catheters requires a certain degree of dexterity. Deltoid triceps transfer is not intended to influence hand control and so a difference in scores for surgical subjects was neither anticipated nor observed. Similarly, this surgical procedure is not felt to be influential in assisting transfers, ${ }^{11}$ but may help in pressure relief. This was echoed by the findings of the present study.

Surgical subjects tended towards higher scores than their controls in two FIM areas-grooming and upper body dressing-indicating greater independence. Statistical significance was not found in this small sample although from descriptions of task accomplishment it appeared that surgical subjects had a higher level of ability than their controls. Grooming necessitates dexterity and control to brush teeth, comb hair, shave etc. The results of FIM evaluation in this study support the improvement shown in grooming tasks following tendon transfer elsewhere. ${ }^{14}$ An improvement in dressing ability has been cited following hand surgery ${ }^{18}$ although no measurement of task performance was carried out. In this study, upper body dressing was generally better in subjects with deltoid triceps transfer, possibly because they were more able, for example, to push their arms into sleeves and therefore required less assistance.

Observation of the total FIM score alone cannot determine the actual task areas which are improved or to what extent. Although other authors have reported increased dependence in subjects interviewed following deltoid triceps transfer, this study showed similar median total FIM scores in these subjects and their controls-28 compared to 33.3. However, interpretation of the subjective results from descriptions of ability and questionnaire responses yields similar conclusions to previous authors who have used interview methods with no apparent scoring system. Improvements were reported subjectively by the surgical subjects. Comments were similar to other anecdotal reports. These comments were particularly useful as it was not possible to show significant differences in the objective tests used. The subjects themselves were in no doubt that surgery had benefited them in many ways and it was apparent during assessment that several subjects had a greater degree of function than their controls. The authors acknowledge the possibility that motivation to achieve functional tasks may be stronger in subjects who have had surgery than those who have not, perhaps because of a desire for a good outcome. However it was not possible to measure the presence or degree of this influence.

In contrast to previously published literature, objective measurements of wheelchair mobility were taken for all subjects. Surgical and control subjects 
were similarly matched on wheelchair type. Results of the mobility tests did not show statistically significant differences, although one surgical subject cited improved wheelchair propulsion as his greatest gain following deltoid triceps transfer. Two surgical subjects were observed to complete the mobility assessments more quickly than their paired controls. The small numbers of data analyzed meant that the result obtained may not be a true reflection of the ability of the total group.

\section{Limitations}

The study was constrained by the sample size and the outcome measures used. All subjects who had undergone deltoid triceps transfer in the area of the study were approached. The outcome measures used were not sufficiently sensitive to detect small changes in function following surgery. This was particularly noticeable in the FIM. It is difficult to identify a scale which can assess the ability to light a cigarette, wipe the nose or adjust bedclothes. These tasks are likely to be possible or be more easily achieved after surgery as a result of improved control of the arm in space, as well as active elbow extension, and could make a huge difference to independence and comfort in individual cases.

\section{Conclusion}

The aim of the study was to investigate the functional capacity of a group of people with deltoid triceps transfer secondary to tetraplegia. They were compared with a group of non-surgical control subjects. The hypothesis that deltoid triceps transfer increases functional independence cannot be fully accepted in view of the results obtained with this sample. There appeared to be a tendency towards greater functional independence in some areas in the surgical group although the differences were not shown to be statistically significant. Subjects' personal reports suggested that surgery had been beneficial.

Although the study findings did not show statistically significant differences, it remains the opinion of these and other authors ${ }^{21}$ that surgical intervention can provide a positive outcome in tetraplegia. Surgery must not be regarded as a solution to poor hand function as a result of limited therapeutic intervention or poor patient compliance. The reservations of those who have undergone surgery are important. Patients considering surgical intervention should be counselled carefully with regard to their expectations, motivation and post-operative regime. Rehabilitation practitioners should consider the potential benefits of surgery but together with the patient, must also continue to strive to achieve the best possible function through nonsurgical efforts. Further investigation of the functional outcome of upper limb surgery in tetraplegia is warranted. It remains a challenge to develop an appropriate method of evaluating the outcome of deltoid triceps transfer.

\section{Acknowledgements}

With thanks to $\mathrm{Mr} \mathbf{J}$ Hobby and Dr F Middleton for permission to study their patients, $\mathrm{Mr} \mathrm{J}$ Goddard and $\mathrm{Mr}$ $T$ Bryant of the Medical Statistics and Computing Department at the University of Southampton, the Inspire Foundation who funded expenses incurred during the study, and the patients themselves for taking part. This work formed part of the MSc in Rehabilitation \& Research completed by Anna Dunkerley at the University Rehabilitation Research Unit, University of Southampton, UK.

\section{References}

1 Allison G, Singer K, Marshall R. Muscle activation patterns during transfers in individuals with spinal cord injury. Aust $J$ Physiotherapy 1995; 41: 169-176.

2 Bergstrom EMK et al. Physical ability in relation to anthropometric measurements in persons with complete spinal cord lesion below the sixth cervical segment. Int Rehabil Med 1985; 7: 51 - 55.

3 Hanson RW, Franklin MR. Sexual loss in relation to other functional losses for spinal cord injured males. Arch Phys Med Rehabil 1976; 57: $291-293$

4 Welch RD, Lobley SJ, O'Sullivan SB, Freed MM. Functional independence in quadriplegia: Critical levels. Arch Phys Med Rehabil 1986; 67: 235-240.

5 De Benedetti M. Restoration of elbow extension power in the tetraplegic patient using the Moberg technique. J Hand Surg 1979; 4: 86-89.

6 Johnstone BR, Jordan CJ, Buntine JA. A review of surgical rehabilitation of the upper limb in quadriplegia. Paraplegia 1988; 26: $317-339$

7 Johnstone BR et al. Surgical rehabilitation of the upper limb in quadriplegia. Aust NZ J Surg 1987; 57: 917-926.

8 Moberg E. Surgical treatment for absent single-hand grip and elbow extension in tetraplegia. J Bone Joint Surg 1975; 57A: $196-$ 205 .

9 Hentz VR, Brown M, Keoshian LA. Upper limb reconstruction in quadriplegia: functional assessment and proposed treatment modifications. J Hand Surg 1983; 8: 119-131.

10 Freehafer AA, Kelly CM, Peckham PH. Tendon transfer for the restoration of upper limb function after a cervical spinal cord injury. J Hand Surg 1984; 9A: $887-893$.

11 Moberg E. Surgical rehabilitation of the upper limb in tetraplegia. Paraplegia 1990; 28: $330-334$.

12 Moberg E. The present state of surgical rehabilitation of the upper limb in tetraplegia. Paraplegia 1987; 25: $351-356$.

13 Lamb DW, Chan KM. Surgical reconstruction of the upper limb in traumatic tetraplegia. A review of 41 patients. J Bone Joint Surg 1983; 65B: $291-298$.

14 Raczka R, Braun R, Waters RL. Posterior deltoid-to-triceps transfer in quadriplegia. Clin Orthop 1984; 187: 163-167.

15 Ejeskar A, Dahllof A. Results of reconstructive surgery in the upper limb of tetraplegic patients. Paraplegia 1988; 26: 204-208.

16 Colyer RA, Kappelman B. Flexor pollicis longus tenodesis in tetraplegia at the sixth cervical level. A prospective evaluation of functional gain. J Bone Joint Surg 1981; 63A: 376-379.

17 Mulcahey MJ, Smith BT, Betz RR, Weiss AA. Outcomes of tendon transfer surgery and occupational therapy in a child with tetraplegia secondary to spinal cord injury. Am J Occup Ther 1995; 49: $607-617$. 
18 Gansel J, Waters R, Gellman H. Transfer of the pronator teres tendon to the tendons of the flexor digitorum profundus in tetraplegia. J Bone Joint Surg 1990; 72A: 427-432.

19 Paul SD et al. Single-stage reconstruction of key pinch and extension of the elbow in tetraplegic patients. J Bone Joint Surg 1994; 76A: 1451 - 1456.

20 Freehafer AA. Tendon transfers in patients with cervical spinal cord injury. J Hand Surg 1991; 16A: 804-809.

21 Schindler L, Robbins G, Hamlin C. Functional effect of bilateral tendon transfers on a person with $\mathrm{C} 5$ quadriplegia. Am J Occup Ther 1994; 48: $750-757$.

22 Hamilton B, Granger C. Guide for the use of the uniform data set for medical rehabilitation. Research Foundation of State University of New York: Buffalo NY, 1990.

23 Dunkerley AL. An investigation into the effect of upper limb tendon transfers on the hand function and functional independence of people with tetraplegia. MSc Dissertation: University of Southampton, 1997.

24 McDowell CL, Moberg EA, House JH. The Second International Conference on surgical rehabilitation of the upper limb in tetraplegia. J Hand Surg 1986; 11A: 604-608.

25 Grey N, Kennedy P. The Functional Independence Measure: a comparative study of clinician and self ratings. Paraplegia 1993; 31: $457-461$.
26 Hamilton BB, Laughlin JA, Granger CV, Kayton RM. Interrater agreement of the seven level Functional Independence Measure (FIM) (Abstract). Arch Phys Med Rehabil 1991; 72: 790.

27 Graves DE, Priebe M, Carter RE. Measurement characteristics of the FONE FIM compared to the FIM (Abstract). Proceedings of 35th Annual Scientific Meeting of IMSOP. Atlanta USA, 1996.

28 Fuhrer MJ et al. Relationship of life satisfaction to impairment, disability and handicap among persons with spinal cord injury living in the community. Arch Phys Med Rehabil 1992; 73: 552 557

29 Smith P, Hamilton BB, Granger CV. FIM Decision Tree: The FONE FIM. Research Foundation of State University of New York: Buffalo NY, 1990.

30 Norris-Baker C, Parris Stephens MA, Hopkins Rintala D Willems EP. Patient behaviour as a predictor of outcomes in spinal cord injury. Arch Phys Med Rehabil 1981; 62: 602-608.

31 Wade DT et al. Walking after stroke. Measurement and recovery over the first three months. Scand J Rehab Med 1987; 19: 25 - 30 .

32 Whalley-Hammell K. Spinal Cord Injury Rehabilitation. Chapman \& Hall: London, 1995. 